\title{
Mulher de favela: interseccionalidades e territorialidades
}

Favela woman: intersectionalities and territories Nilza Rogéria de Andrade Nunes*

\begin{abstract}
Resumo - Este artigo tem como objetivo refletir sobre quem são e o que fazem as mulheres publicamente reconhecidas por sua atuação social e política nas favelas do Rio de Janeiro. O estudo assume o ponto de vista histórico de que esta mulher de favela que se expressa e se manifesta como ativista social vem se construindo, principalmente, a partir da década de 1990. Do ponto de vista metodológico, o estudo parte de um mapeamento utilizando entrevistas semiestruturadas com 100 mulheres de diversas favelas, todas identificadas e reconhecidas como lideranças comunitárias. Os resultados apontam que a partir das evidências e sinergias reconhecemos o crescente protagonismo feminino nos territórios segregados socioespacialmente. Esse se dá a partir de sua atuação enquanto sujeito político coletivo, que age no enfrentamento cotidiano das iniquidades que acometem os espaços populares e na afirmação de uma sociedade democrática e participativa.
\end{abstract}

Palavras-chave: mulher; feminização do poder; favela.

\begin{abstract}
This article aims to reflect on women publicly recognized for their social and political performance in the favelas of Rio de Janeiro, who they are, and what they do. The study assumes the historical point of view that this favela woman who expresses and manifests herself as a social activist has been being built mainly since the 1990s. From a methodological point of view, the study starts with a mapping using semi-structured interviews with 100 women from various favelas, all identified and recognized as community leaders. The results indicate, from the evidence and synergies, that the growing female role in the socio-spatially segregated territories can be recognized. This happens from their performance as a collective political subject who acts in the daily confrontation of inequities that affect popular spaces, and in the affirmation of a democratic and participatory society.
\end{abstract}

Keywords: woman; feminization of power; favela.

\footnotetext{
* Assistente Social; Pós doutoranda em Saúde Coletiva pela UnB; Doutora em Serviço Social pela PUC-Rio com estágio doutoral subsidiado pela CAPES na Universidade de Dundee - Escócia - Reino Unido. Possui Mestrado em Psicossociologia de Comunidades e Ecologia Social pela UFRJ e Graduação em Serviço Social também pela UFRJ. Atualmente é Professora de Graduação e Pós-Graduação do Departamento de Serviço Social da PUC-Rio. E-mail: nr.nunes@puc-rio.br. ORCID: https://orcid.org/0000-0002-2208-1054.
} 


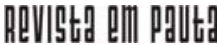

\} MULHER DE FAVELA - NUNES, N. R. A. \}

DOI: $10.12957 /$ rep.2021.56073

\section{Introdução}

Nos locais onde as desigualdades tornam-se acentuadamente expressões múltiplas de vulnerabilidades sociais, encontramos um sujeito político que vem atuando com estratégias, disponibilidade e ousadia. Estamos falando das (re)conhecidas lideranças comunitárias ${ }^{1}$ ou o que chamamos "mulher de favela". Essas protagonistas aqui em cena estão geopoliticamente localizadas nos territórios segregados socioespacialmente a que se nomeia "favelas" no Rio de Janeiro e cujo reconhecimento público veio se construindo a partir dos anos 1980, ganhando impulso e visibilidade a partir da década de 1990.

Num lócus que permeia o tecido urbano da cidade do Rio de Janeiro, as favelas constituem-se e se expressam num mosaico de violências e violações de direitos. No entanto, ainda que sejam esses locais notadamente demarcados por fronteiras (in)visíveis, as mulheres vêm fazendo existência e resistência. As popularmente nomeadas lideranças comunitárias, ou ativistas sociais, vêm construindo e consolidando seu lugar e protagonismo. Com pautas diversas, essas mulheres subvertem a ordem que historicamente as colocou em condições de subalternidade e vêm conquistando espaços de luta em uma escala micro, local, mas que trazem consigo um projeto de cidade e de país.

Este estudo está baseado em uma pesquisa em curso ${ }^{2}$ cujo objetivo é refletir sobre quem são e o que fazem as mulheres publicamente reconhecidas por suas atuações sociais e políticas nas favelas do Rio de Janeiro. Buscamos, ainda, compreender o fenômeno da feminização do poder nos espaços populares a partir de um mapeamento das lideranças femininas que articulam suas práticas aos sentidos coletivos amplos. Até o presente, realizamos 100 entrevistas com mulheres que são publicamente reconhecidas como pessoas de referência nos seus territórios. Essas atuam na saúde, na educação, na cultura, no meio ambiente, na segurança pública e onde mais puderem se fazer presentes. Promovem a mobilização comunitária, articulam políticas públicas, participam de espaços de controle social, fazem advocacy por seus locais de moradia, entre tantas outras ações.

A construção cotidiana dessa mulher e seu lugar de destaque social e político se conforma através de práticas e atitudes que evidenciam que há um protagonismo dessa mulher em condições de subalternidade. Falar dessas lideranças é falar de um corpo estético-político, uma vez que traz experiências singulares de exclusão, a quem homologamos falar da mulher negra em sua grande maioria.

Ser negra e ser mulher no Brasil é ser objeto de tripla discriminação, uma vez que os estereótipos gerados pelo sexismo, pelo racismo e

\footnotetext{
${ }^{1}$ Optamos por utilizar a palavra liderança italicizada por se tratar de uma expressão cotidianamente utilizada na linguagem da favela para fazer referência a uma pessoa que se destaca das demais nos termos aqui descritos.

2 Esta pesquisa conta com o apoio do CNPq e da FAPERJ.
} 
pela classe social a coloca na extremidade da condição subalterna, aqui acrescida ainda pela dimensão territorial. Nessa perspectiva interseccional, essas mulheres subvertem a ordem e desenvolvem um modo particular de fazer política. Fazem gestão de territorialidades (redes) que se constroem como teias no interior do território da favela e se engajam na busca de transformação de um coletivo que transcende suas relações pessoais. Em uma escala micro local que nos compete explorar, o exercício do poder dessa mulher, ainda que desempenhado de forma simbólica, produz mudanças efetivas na vida da favela devido à sua capacidade de se articular com as políticas públicas, com os movimentos sociais, com coletivos e com quem mais estiver ao seu alcance.

Elas transcendem o local, acessam a cidade, o estado e muitas vezes o país, num movimento permanente em defesa da cidadania dos moradores de seus territórios e na afirmação de uma sociedade democrática e participativa, nos ensinando que é necessário examinar como as experiências participativas dessas mulheres vêm se construindo como espaços de luta no enfrentamento das desigualdades sociais e em prol da sua cidadania e dos demais moradores das favelas onde vivem.

Para tais reflexões, estamos tratando de um poder que rompe com as fronteiras demarcadas pelo colonialismo e pelo racismo. Estamos falando de mulheres - negras e pobres - que trazem no corpo múltiplas expressões de uma sociedade marcada pela opressão, pelo patriarcado e pela desigualdade. Junto a essas incorporamos as brancas, igualmente pobres e moradoras das favelas, e que também estão subjugadas às tais condições de opressão. Assim, ancoramos nossas reflexões principalmente nos referenciais do feminismo negro, nos estudos decoloniais e na concepção da favela como espaço geopolítico demarcado por uma sociabilidade que se estabelece nas contradições entre suas ausências e violências, mas também pelas presenças que se estabelecem pela solidariedade e laços de vizinhança.

\section{Aprendizados com a interseccionalidade}

Vivemos em uma sociedade de classes, que estratifica os acessos aos direitos e à liberdade. Como o tema em questão trata das mulheres, iniciamos nossas reflexões a partir de uma breve explanação acerca do que essa categoria nos revela.

Para as mulheres, se acrescem as desigualdades de gênero e poder, que por vezes são tidas como naturais, atribuídas a uns e outros, conforme sinaliza Piscitelli (2009). No entanto, as relações de poder são determinadas por marcadores sociais que se conformam em construções identitárias. Nesse sentido, destaca Saffioti (2009, p. 82) que "mais do que papéis sociais que se aprende nos processos de socialização, são as identidades sociais (gênero, 
raça e etnia, classe) que vão gestando a subordinação, a partir das experiências vividas que colocam as mulheres nesse lugar".

Angela Davis (2016) e bell hooks (2014) argumentam criticamente a "estabilidade homogeneizante da categoria 'mulher' e a necessidade de se atentar igualmente às formas combinadas de diferenciações e desigualdades como 'raça' e classe social, entrecortando as experiências de muIheres" (HENNING, 2015, p. 107), o que podemos considerar como um "sistema de opressão interligado (AKOTIRENE, 2019, p. 21). Do ponto de vista das suas pertenças raciais, lembramos com Jurema Werneck, Mendonça e White (2000) que as mulheres negras não são todas iguais, nem são completamente diferentes; mas, conforme destacaram Davis (1981) e hooks (1981), a racialização possibilitou conquista de espaço político e afirmação da identidade dessas mulheres, impulsionando os sentidos de fazerem ecoar suas vozes.

Não cabe aqui reproduzir a historicidade desse processo, mas sim pontuar suas marcas na identidade do povo brasileiro, em especial dessas mulheres. A partir do final do período colonial a configuração do lugar da mulher negra na sociedade brasileira manteve-se no lugar de sempre: na "periferia" da família patriarcal, com seu uniforme, avental e espanador. Não estar nesse lugar de serviçal da família a levou para serviçal nos outros espaços ocupacionais da sociedade capitalista, nos quais estiveram a ela reservados os lugares das condições mais subalternas entre as subalternas reservadas às mulheres até os dias de hoje. Assim, "ser negro é enfrentar uma história de quase quinhentos anos de resistência à dor, ao sofrimento físico e moral, à sensação de não existir, à prática de ainda não pertencer a uma sociedade na qual consagrou tudo o que possuía, oferecendo ainda o resto de si mesmo" (NASCIMENTO, 1974 apud RATTS, 2006, p. 98).

Ao homologarmos o sujeito político das mulheres de favela que exercem um papel de liderança, estamos relacionando uma confluência de opressões que recaem sobre essas e as outras mulheres que coabitam o espaço da favela. Para tal, trazemos as dimensões de gênero, raça e classe que nos remetem à noção de interseccionalidade propagada por Kimberlé Crenshaw (2002). Embora muitas vezes seja creditada a ela a triangulação desses termos, esse advém do black feminism e dos movimentos abolicionistas do século XIX. Importa-nos refletir, no entanto, acerca da confluência entre ações e políticas específicas que geram essas opressões quando adicionamos a localização geográfica de onde advêm, o que potencializa as violências de gênero. Essas estruturas se intensificam, vulnerabilizandoas em uma ou mais categorias simultaneamente. Assim, a interseccionalidade, conforme sinalizada por Akotirene (2019), vai além quando propõe enfrentar questões de violência contra as mulheres, verificar a identidade produzida pelo racismo, exploração de classe, patriarcado e homofobia. 
Seguindo algumas teóricas do feminismo negro (GONZALEZ, 1982; hooks, 2014; CARNEIRO, 2002; COLLINS, 2016; WERNECK, 2016; AKOTIRENE, 2019; KILOMBA, 2019), podemos afirmar como as opressões estruturais estariam interconectadas numa matriz de dominação que influencia todos os níveis das relações sociais e perpassa os planos individuais e coletivos, e como essas estruturas são visíveis e permeáveis quando nos referimos às mulheres das favelas. No entanto, evidenciamos que elas subvertem essa ordem e rompem com esses limites impostos pela estrutura social vigente.

Suas construções identitárias nos chamam a atenção para o que, segundo Cheryk Gilkes (1981), remete a resistência de mulheres negras à opressão que vivenciam, sendo constantes as ameaças ao status quo. Como forma de punição e de controle são construídas diversas imagens negativas e degradantes sobre elas. Segundo Collins (2016), os estereótipos negativos, os corpos hipersexualizados e o mito de que são mais resistentes à dor e às outras formas de exploração - no contraponto das mulheres brancas, associadas à imagem da fragilidade e da docilidade - definem as mulheres negras como "um outro negativo, a antítese virtual da imagem positiva dos homens brancos" (COLLINS, 2016, p. 105). Isso corrobora com o que hooks (2014) aponta como a construção da imagem e da identidade da mulher negra a partir da interpretação do outro. "É da mulher negra o coração do conceito da interseccionalidade" (AKOTIRENE, 2019, p. 24).

Ao trazermos para o centro da reflexão o devir dessa mulher de favela, consideramos que o papel ocupado pelas mulheres negras intelectuais nos discursos sobre racismo e sexismo remete a passos que vêm de longe. A década de 1980 aponta com clareza para o fato de que a inserção da temática racial ganha espaço no debate feminista, uma vez que as implicações dos legados sociais do período escravocrata na vida das mulheres negras eram, até então, ignoradas pelo movimento feminista. Da mesma forma, as práticas machistas decorrentes do modelo patriarcal estavam presentes no interior do próprio Movimento Negro Unificado, o que impedia a inclusão das agendas políticas da mulher negra em ambos os projetos políticos.

Duas iniciativas marcam esse processo de mobilização das muIheres negras e, dentre essas, muitas mulheres de favela: o Nzinga - Coletivo de Mulheres Negras -, em 1983, e o Centro de Mulheres de Favelas e Periferias (CEMUFP), que contava com a atuação de diferentes representações de favelas. Elas atuaram dentro e fora das favelas, dos partidos, do movimento feminista e de mulheres negras, do movimento negro, do movimento de favelas e de associações de moradores (WERNECK, 2011).

No entanto, as dificuldades para o estabelecimento de conexões do movimento de mulheres negras com o movimento feminista, cujas marcas foram reveladas pelas desigualdades estruturais e diferenças políticas, começaram a despontar nos encontros para discussão e construção de uma pauta política. Nesse contexto, cabe destacar o III Encontro Feminista Latino- 
Americano e do Caribe, realizado na cidade de Bertioga, em São Paulo, em 1985. Naquele evento, entra em cena outro segmento de mulheres que até então não havia demarcado o seu "lugar de fala" na luta: as mulheres de favela do Rio de Janeiro.

Esse encontro traz uma marca importante para este estudo, uma vez que, segundo Matilde Ribeiro (2008), um ônibus vindo do Rio de Janeiro com mulheres negras de movimentos de bairro (favelas e periferia) e demais setores, como partidos políticos, reivindicavam sua participação no encontro sem realizarem inscrição sob a alegação de não terem recursos para tal. Afirmavam, ainda, terem vindo para ficar. Marcando posição, as negras que estavam no ônibus e outras participantes do evento alegavam o direito de participação frente ao grupo organizador (composto em sua maioria de mulheres brancas). Esse conflito expressou uma marca pelas diferenças raciais, mas também pelas questões de classe.

Ainda que já participantes ativas, enquanto mulheres negras e pobres, dessa vez elas marcam seu lugar como "mulheres de favela". Essa presença acentuou o debate sobre inclusão e exclusão, fazendo emergir também o debate sobre questões de raça e classe, que de fato até então não ocupavam o mesmo lugar, demarcando um espaço de luta no qual "[...] os privilégios de classe, raça e de orientação sexual hetero estruturaram as relações de poder entre as mulheres na sociedade e dentro do próprio feminismo" (ALVAREZ et al., 2003, p. 548).

Esse episódio teve segmento e, em 1988, as mulheres negras deram impulso à construção de uma agenda própria, intensificando as reflexões acerca das opressões racial e de gênero (RIBEIRO, 2008, p. 450). Foi a partir do surgimento do Coletivo de Mulheres Negras que essa agenda se conformou, afirmando uma pauta política própria. As mulheres negras em seu processo político entenderam que "não nasceram para perpetuar a imagem de 'mãe preta' [...] e que desigualdades são construídas historicamente, a partir de diferentes padrões de hierarquização constituídos pelas relações de gênero e raça que, mediadas pela classe social, produzem profundas exclusões" (RIBEIRO, 2008, p. 988).

Quando se coloca como questão política outra demanda para as mulheres negras, considera-se o negro não como uma vítima da sociedade, mas como um participante ativo da construção sócio-histórica do país. Nesse sentido, falar dessa mulher é falar de um corpo estético-político, uma vez que o corpo traz experiências singulares de exclusão (CARNEIRO, 2002). A representação da mucama, mãe preta, transportada para a mulata, empregada doméstica e babá, traduzia certas imagens que confinam as mulheres negras a determinados lugares e papéis sociais, restringindo-as ao sexo e ao trabalho manual, em particular das casas de família (HEILBORN; ARAÚJO; BARRETO, 2010). Isso gera uma espécie de "asfixia social", com desdobramentos negativos sobre todas as dimensões da vida. "Ser negra e mulher no Brasil, repetimos, é ser objeto de tripla discriminação, uma 


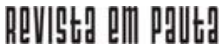

\} MULHER DE FAVELA - NUNES, N. R. A.

DOI: $10.12957 /$ rep.2021.56073

vez que os estereótipos gerados pelo racismo e pelo sexismo a colocam no mais baixo nível de opressão" (GONZALEZ, 1982, p. 97).

Essa construção imagética e naturalizada constitui a "[...] dimensão abjeta desses corpos negros" e ainda que "[...] não considerados inteligíveis e, portanto, destituídos de legitimidade política e normativa, existem e resistem" (CANTO, 2012, p. 45). Ainda sobre o devir mulher negra, Vanessa Santos do Canto (2012) argumenta com Franz Fanon (1983) que a liberdade é o seu destino, uma vez que o corpo que marca o seu processo de identificação o retrai a uma construção orgânica de sua história. Assim, "[...] o mesmo corpo que a torna mulher negra deve ser seu instrumento de subversão" (CANTO, 2012, p. 47), o que traz para o centro do debate uma construção política própria e legítima.

Essa liderança comunitária que, como sinalizado acima, nomeamos mulheres de favela é um sujeito político que se constrói a cada dia. Do ponto de vista histórico elas vêm se construindo, principalmente, a partir da década de 1990, e geopoliticamente se inserem nos territórios segregados socioespacialmente. Fazem do seu cotidiano uma história de luta e de tomada de consciência permanentes, reinventando uma práxis ${ }^{3}$ política e trazendo em si a inquietude de uma revolução silenciosa de comportamentos (DEL PRIORI, 2009), cuja liberdade se anuncia todos os dias.

Ao trazermos para o centro do debate a emblemática frase de Gayatri C. Spivak (2014) "pode a subalterna falar?" - e que a autora afirma que não -, somos provocados a refletir sobre as estruturas de poder que silenciam, uma vez que "está confinada à posição de marginalidade e silêncio que o pós colonialismo prescreve" (KILOMBA, 2019, p. 47). Mas esse "silêncio" está alinhado aos "corpos subordinados", o que sugere "uma dinâmica na qual a negritude significa não somente 'inferioridade', mas também estar fora do lugar, enquanto a branquitude significa estar no lugar" (KILOMBA, 2019, p. 56). Mas é preciso falar, e alto! E é preciso ouvir o que elas têm a dizer. É preciso "desfazerem rotas hegemônicas da teoria feminista e maternarem a-feto, de si, em prol de quem sangra, porque o racismo estruturado pelo colonialismo moderno insiste em dar cargas pesadas a mulheres negras [...] (AKOTIRENE, 2019, p. 21-22).

É necessário e urgente romper com a "colonialidade do poder" (QUIJANO, 2005), a cuja dominação centrada na questão da raça e na divisão do trabalho foi estruturalmente associada, reforçando-se mutuamente, apesar de que nenhum dos dois era necessariamente dependente do outro para existir ou para transformar-se (QUIJANO, 2005). Assim, é preciso insurgir contra a matriz colonial de poder que faz o controle da economia, da autoridade, do gênero, da sexualidade, do conhecimento e da subjetividade.

${ }^{3}$ A filosofia da práxis é, para Gramsci, construção de vontades coletivas correspondentes às necessidades que emergem das forças produtivas objetivadas ou em processo de objetivação, bem como da contradição entre estas forças e o grau de cultura e de civilização expresso pelas relações sociais (GRAMSCI, 1987). 
Nesse sentido, o conceito de "colonialidade do ser" (MALDONADO-TORRES, 2016) que nos leva a compreender como "relacionado ao processo de desumanização" (LUGONES, 2014, p. 938), aponta que a "a atitude decolonial encontra suas raízes nos projetos insurgentes que resistem, questionam e buscam mudar padrões coloniais do ser, do saber e do poder" (MALDONADO-TORRES, 2016, p. 88).

Estamos atentas às novas representações sobre as favelas que se materializam nas falas, sobretudo quando os sujeitos que falam são considerados - e se consideram - pessoas de referência. Examinar as tensões, representações e práticas das mulheres nesses contextos de exercício, cujas agências as consolidam no poder em âmbito local, nos permite afirmar que há em curso uma "feminização do poder" (FONSECA; PAGNOCELLI; MAGALHÃES, 2008) nesses espaços populares. Isso porque esse pode ser compreendido como um processo histórico da conquista feminina de acesso às estruturas de poder culturais, sociais, econômicas e políticas. Assim, se faz necessário e urgente examinar como e a partir de quais relações específicas, no tempo e no espaço, as experiências participativas da mulher de favela se deram e permanecem até hoje nas organizações de base comunitária, nos movimentos, nos coletivos, nas instituições religiosas, em iniciativas individuais, dentre tantas outras formas de inserção, mas que convergem na construção de espaços de luta por políticas públicas que asseguram garantia de direitos em prol da sua cidadania e dos demais moradores.

\section{Mulheres e as suas territorialidades}

O lócus desse estudo é a favela, muitas vezes também referenciada como comunidade ou território por parte de seus moradores, do poder público e da sociedade em geral. Muito embora nossa compreensão de cidade se dê de forma integral, o recorte socioespacial a que a mesma se refere especifica o que objetivamente pretendemos explorar.

No imaginário social está estabelecida uma relação entre duas cidades distintas: a favela e o asfalto, ou a favela e o restante da cidade. A essa primeira, a representação da desordem, do medo, do local de moradia da "classe perigosa" (VALLADARES, 2000), acompanha o imaginário dos habitantes da cidade desde o final do século XIX até hoje. Ao "asfalto" está associada a imagem do local digno de se viver.

No entanto, a favela exerce um papel essencial para a cidade: geográfico, econômico, social e político. Ela é parte da cidade, embora historicamente tenha tido recusada sua existência devido à imagem negativa, sinônimo de insegurança e violência. Essa visão homogeneizadora, bem como o discurso voltado quase que exclusivamente para as ausências, corrobora com a imagem construída de não reconhecimento do morador de 


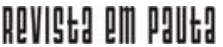

\} MULHER DE FAVELA - NUNES, N. R. A. \}

DOI: $10.12957 /$ rep.2021.56073

favela como um agente ativo e atuante, inserido no tempo e no espaço da cidade - portanto, cidadão sujeito de direitos. Demarcada por fronteiras físicas e simbólicas, conformam áreas de separação e contato de "práticas socioespaciais que se desenham na paisagem, que marcam e individualizam lugares e formas de pertencimento e que expressam territorialidades e formas de apropriação do urbano" (FERNANDES, 2012, p. 160).

Buscando um entendimento nosso do que seja "favela", nos valeremos da sistematização conceitual realizada por Lícia Valladares (2005) e compartilhada por vários autores (TELLES, 2006; FERNANDES, 2012), que lhe confere um diálogo entre a irregularidade da ocupação do espaço urbano, pobreza e violência com manifestações culturais que constroem marcas de identidade. Traz a marca do território urbano dos pobres - uma "cidade dentro da cidade" -, enclave e território da partição, símbolo da segregação socioespacial, mas que traz o sentido de comunidade, onde se evidencia uma realidade plural e multifacetada.

Isso se contrapõe à compreensão estereotipada que o imaginário social do conjunto da cidade reconhece como favela, sempre associada à reprodução do lugar subalterno e ao estigma de hoje da cultura da violência. Há prevalência da representação do que a favela não tem, e pouco se compreende sobre a solidariedade, as relações de vizinhança, a representação cultural e a força do povo, que de fato faz um movimento, ainda que silencioso, de permanente resistência à lógica da "exclusão".

Quando nos referimos à favela, por vezes também a chamamos "comunidade", já que essa é uma forma comum de como seus moradores a nomeiam. Chamam também território - nomenclatura essa amplamente utilizada pelas políticas públicas para designar delimitações geográficas. No entanto, quando trazemos a noção de território, o fazemos na perspectiva do vivido, uma vez que em qualquer acepção tem relação com o poder no seu sentido mais concreto, de dominação, mas também no sentido mais simbólico, de apropriação (HAESBAERT, 2004).

Em diálogo com Lefebvre (1986), esse estabelece uma distinção entre apropriação e dominação ("possessão", "propriedade"). A primeira é um processo muito mais simbólico, carregado das marcas do "vivido", do valor de uso; a segunda, mais concreta, funcional e vinculada ao valor de troca, que para o autor deveriam caminhar juntas. Assim, enquanto "espaçotempo vivido", o território é sempre múltiplo, "diverso e complexo", imerso em relações de dominação e/ou de apropriação sociedade-espaço, "desdobra-se ao longo de um continuum que vai da dominação político-econômica mais 'concreta' e 'funcional' à apropriação mais subjetiva e/ou 'cultural-simbólica" (HAESBAERT, 2004, p. 95-96).

Quando nos referimos às territorialidades, nossa compreensão perpassa o território entendido como "um campo de forças que entre as várias articulações possíveis se dá como uma rede de relações sociais que ganha sentido por sua complexidade interna" (NÓBREGA, 2013, p. 12). 


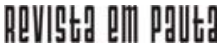

\} MULHER DE FAVELA - NUNES, N. R. A. \}

DOI: $10.12957 /$ rep.2021.56073

Sendo assim, essa é "identificada pelo conjunto de práticas sociais que são definidas pelas relações de poder e pela apropriação simbólica de uma área geográfica por grupos e indivíduos, colocando assim o território como a manifestação dessa territorialidade" (NÓBREGA, 2013, p. 13).

Ao nos referimos às mulheres no exercício de suas territorialidades, buscamos compreendê-las a partir de suas ações e conexões que desenham complexas territorialidades, em geral na forma de territórios-rede. Esse termo está ligado a "como elas próprias se organizam no espaço e como elas dão significado ao lugar" (HAESBAERT, 2004, p.22).

O poder que buscamos compreender no âmbito deste estudo está relacionado como sendo a "multiplicidade das relações de força que são imanentes ao domínio em que elas se exercem e são constitutivas de sua organização. O poder é parte intrínseca de toda uma relação" (RAFFESTIN, 1993, p. 54). Contudo, o poder não é único e nem é possível de achálo materializado. Está em todo lugar, não a partir de uma lógica universalizante, mas brota de todos os lugares e se manifesta nas relações quando dois polos fazem face um ao outro ou se confrontam. Dessa forma, entendemos o poder como multidimensional, e essa postura incentiva um olhar para as relações cotidianas, para as relações de poder em todas as escalas.

É com um conhecimento acumulado pelas vivências que se interpreta a realidade. Os saberes são elaborados sobre e a partir da experiência concreta por essas mulheres, da mesma forma que se faz necessário reconhecer que cultura popular que vem dos saberes do povo é também a "memória da alternativa [...] uma exigência, sempre postergada e longínqua, da realização de justiça" (CHAUÍ, 1990, p. 63).

Nossa discussão aponta para a necessidade de chamar a atenção sobre a valorização das mulheres nas políticas sociais contemporâneas. Os discursos ancorados na noção de empoderamento e protagonismo feminino requerem amplo debate acerca dos estereótipos que circundam essa visão de gênero, corresponsabilizando as mulheres em diversas circunstâncias. Isso porque, na hierarquia das relações sociais, sempre foram associadas ao patamar inferior e o homem ao superior. Quando relacionamos ao protagonismo que essas mulheres exercem, estamos focando no seu engajamento em lutas por justiça social e cidadania.

\section{Quem são as mulheres de favela?}

A pesquisa ${ }^{4}$ em curso traz como intencionalidade ampliar a necessária visibilidade sobre a luta social e política das mulheres que assumem o lugar de liderança diariamente nos territórios populares. Para tal, elegemos identificar essas mulheres a partir da metodologia snowball sampling, ou

${ }^{4}$ Esta pesquisa foi aprovada pelo Comitê de Ética em Pesquisa da PUC-Rio - Parecer nº 44/2018. 


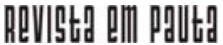

\} MULHER DE FAVELA - NUNES, N. R. A. \}

DOI: $10.12957 /$ rep.2021.56073

"bola de neve" (VELASCO; DÍAZ DE RADA, 1997). No método snowball os participantes iniciais indicam novos participantes, e assim por diante (BIERNACKI; WALDORF, 1981). Esse processo de trabalho pode ser descrito como a obtenção de dados ou informações sobre características, ações ou opiniões de determinado grupo de pessoas, indicado como representante de uma população-alvo, por meio de um instrumento de pesquisa. Essa é uma técnica de amostragem não probabilística que utiliza cadeias de referência, numa espécie de rede (ALBUQUERQUE, 2009).

A busca ativa das lideranças femininas das favelas vem se dando a partir de contatos, aproximações, indicações e participação em locais que essas mulheres frequentam (fóruns da sociedade civil, redes de comunidades, entre outros). Assim sendo, a seleção das sujeitas da pesquisa se dá a partir da atuação dessas mulheres como participantes ativas, que se reconhecem e que são publicamente reconhecidas por seu ativismo em suas comunidades há, pelo menos, um ano. Esse reconhecimento e sua atuação sociopolítica é o nosso principal critério de seleção. Não possuímos a delimitação do lócus do estudo, considerando que essa busca nos aponta colaboradoras que advêm de todas as regiões da cidade do Rio de Janeiro, o que não possibilita prever quem e de onde são ou serão. Também não há recorte espacial previamente definido, uma vez que o convite à participação desse estudo se dá de forma espontânea.

As reflexões aqui apresentadas se baseiam nas 100 primeiras entrevistadas que estão registradas em um banco de dados no Statistical Package for the Social Sciences (SPSS) - um software aplicativo de gerenciamento e análise de dados em pesquisa qualitativa. Essas correspondem a $50 \%$ da meta prevista inicialmente. Até este momento do estudo, podemos afirmar que não houve resistência à participação na pesquisa; pelo contrário, há um reconhecimento público e expresso acerca da importância e legitimidade desse.

Um lugar no mapa é também um lugar na história. Citada por Margareth Rago (2013, p. 313), essa frase da escritora, poeta, professora e militante feminista Adrienne Rich nos faz reconhecer que cada uma das colaboradoras que dá vida a este estudo, em seus territórios e com suas territorialidades, construiu e constrói a sua e muitas outras histórias.

As vozes dessas mulheres narram e desenham outra forma de exercitar uma práxis política, que transforma suas inquietudes em pontes, articula e conecta diferentes possibilidades de ação, transformando a si e ao seu coletivo em um movimento virtuoso por mudança social (RAGO, 2013). Para descrever tal processo, apresentaremos o perfil dessas mulheres, tomando-as como porta-vozes de uma afirmação individual e coletiva. Elas não são somente as moradoras das favelas. São as mulheres que trazem em si um sentido de luta.

Nossas participantes são majoritariamente negras, correspondendo a 90\% das entrevistadas; 80\% são mães; 49\% casadas; 50\% são as principais 
responsáveis pela renda familiar. Com relação à religião, 30\% declararamse evangélicas, $25 \%$ sem religião, $17 \%$ católicas e os $18 \%$ restantes distribuem-se entre umbandistas, candomblecistas, budistas, dentre outras. $\mathrm{O}$ dado referente à religião nos surpreendeu, uma vez que estudos apontam que a Igreja Católica foi determinante na formação de lideranças em décadas anteriores através das pastorais e da própria atuação nas favelas e periferias.

No Rio de Janeiro, diversas organizações de base comunitária surgiram a partir dos anos de 1990, focalizando o debate sobre a necessidade de reconhecimento social da mulher, enfrentando um desafio para a mobilização de recursos públicos que promovessem melhorias efetivas nas condições de vida de seus territórios. Nesse sentido, 66\% estão vinculadas a uma organização e $96 \%$ participam de espaços coletivos (movimentos sociais, redes, coletivos, dentre outros). Assim, a atuação em rede (seja ela construída dentro da própria favela ou fora dela) e a participação nos movimentos sociais e na luta por políticas públicas que contemplam as necessidades - individuais e coletivas - remetem para a necessária e importante visibilidade acerca do que essas mulheres vêm fazendo. Essa luta contribuiu diretamente para ampliação de direitos e efetivação da cidadania, cooperando plenamente para o desenvolvimento de aspectos que interferem na autonomia feminina e nos processos de superação das desigualdades. Ao declararem atuar em diversas frentes, hierarquizam em primeiro lugar a assistência, a educação e a saúde.

Elas estão nas favelas, mas também na cidade. Nesse sentido, nos interessa conhecer a participação das ativistas sociais moradoras de favela nessa ação micropolítica de mobilização e negociação com o poder público. Essas mulheres, sujeitas com agências, estão criando determinados repertórios para enfrentar a estrutura desigual a que estão permanentemente submetidas. Reconhecem que o Estado não age para amenizar os conflitos postos pelas desigualdades e para garantir formas de melhor viver nas favelas, mas não se acomodam. Realizam ações de diferentes naturezas: trabalham com educação, saúde, cultura, meio ambiente, violência contra mulher, terapia do riso, educação menstrual, segurança alimentar, entre tantas outras atividades.

É no acesso à qualificação educacional que podemos afirmar isto: $42 \%$ possuem nível superior completo, sendo $12 \%$ com pós-graduação. Se acrescentarmos as participantes que declaram possuir o ensino superior incompleto, esse percentual alcança $66 \%$. Esse dado é bastante importante, pois se esse processo faz uma curva ascendente a partir dos anos de 1990, com uma culminância na última década, isso é reflexo direto do ingresso às universidades possibilitado a partir das políticas de acesso e permanência, seja por meio das cotas raciais, Prouni ou Fies. Essas informações nos possibilitam construir um perfil acerca dessas mulheres - possuem uma vida dentro e fora da favela. Essa capacidade de circulação na cidade as torna autônomas e com mais liberdade para construir os caminhos que as levam 


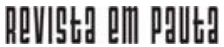

\} MULHER DE FAVELA - NUNES, N. R. A. \}

DOI: $10.12957 /$ rep.2021.56073

a resolver a vida: sua, de suas famílias e de suas comunidades - aqui no sentido genuíno que o termo sugere: o lugar de pertencimento, das relações de vizinhança, da solidariedade. Elas estudam ou estudaram, mas não abandonaram seu lugar de pertencimento. Articulam-se e trazem o conhecimento para dentro dos seus locais de atuação e moradia.

Essas ativistas sociais enquadram-se, em sua maioria, em preceitos raciais, culturais ou econômicos de marginalização, o que as têm levado a se organizarem, a fim de modificar suas condições de vida. Participam de redes, coletivos, movimentos sociais, instituições religiosas, conselhos de direitos e, em menor grau, de partidos políticos - ou seja: atuam em rede. Os nós das redes são lugares de conexões que, de acordo com Raffestin (1993), correspondem a lugares de poder e de referência. É através desses pontos que a rede solidariza, mas também exclui. Assim procuram identificar e dar visibilidade às múltiplas formas de enfrentamento das iniquidades sociais a que estão permanentemente submetidas, e que se posicionam, se articulam e atuam utilizando saberes, práticas e estratégias locais, onde são protagonistas quando exercem esse papel de liderança.

Curiosamente, $68 \%$ se declaram feministas, mas as $32 \%$ que não se identificam com o termo trazem, em sua grande maioria, uma justificativa feminista: "Não sei dizer se eu sou feminista; o feminismo é pouco para mim; luto pelos direitos do povo em geral (homem, mulher, homossexual) sem discriminação de cor, raça, sexo". Curiosamente a negação traz significados e significâncias cujas práticas e atitudes que preconizam agem no enfrentamento dos problemas que permeiam os seus locais de moradia e que muitas vezes se alinham ao feminismo. No entanto, a justificativa de suas negações está majoritariamente alinhada à crítica aos feminismos radical e liberal, cujas práticas elas identificam e declaram não concordar. Mas essas mulheres subvertem a ordem e desenvolvem um modo particular de uma consciência feminista feminina, considerando o que Lebon (2014) nomeia de "feminismo popular". Inquieta-nos, ainda, se tais atuações se refletem sobre o campo feminista que se pode compreender como "feminismo em movimento" (ALVAREZ, 2014) ou mesmo o chamado "popular feminismo" (VEILLETTE, 2019). Esses se entrecruzam com as questões relacionadas aos estudos feministas que apontam para novas reflexões no âmbito brasileiro e latino-americano, nos apresentando possibilidades que poderão subsidiar outros estudos.

Elas saem em busca de (re)conhecimento e diversificação das concepções e práticas políticas. O que a ótica das mulheres dos grupos subalternizados introduz no feminismo é, conforme destaca Carneiro (2002, p. 3), "o resultado de um processo dialético que, se, de um lado, promove a afirmação das mulheres em geral como novos sujeitos políticos, de outro exige o reconhecimento da diversidade e desigualdades existentes entre essas mesmas mulheres". 


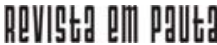

\} MULHER DE FAVELA - NUNES, N. R. A. \}

DOI: $10.12957 /$ rep.2021.56073

\section{Considerações finais}

Numa breve (in)conclusão, uma vez que este estudo se encontra em andamento, compreendemos que o compromisso com a transformação social está no horizonte dessas mulheres, que se constrói com práticas e atitudes. A interseccionalidade as atravessa e são expressão do gênero, da raça e da classe a que pertencem, associados à dimensão territorial, traduzindo-se nesse grupo como existência e resistência.

A experiência vivida e os diferentes caminhos para enfrentar a realidade que envolve suas vidas pessoais e dos demais moradores de suas comunidades evidencia a luta dessas mulheres em uma esfera que é pública, porém não estatal. Por essas e outras razões expressas até aqui é que podemos afirmar que a "feminização do poder" é, de fato, um movimento que emerge no cenário atual, compreendendo que há um protagonismo da mulher em condições de subalternidade.

Vive a diversidade. Na favela há toda sorte de diferenças de pertenças e projetos. Independente das diferenças de atuação onde se consolidam suas práticas, ela busca respeitar o outro, aceitando e/ou valorizando saberes e escolhas. Esse sujeito, com consciência "de si" e "para o outro", atua a partir da solidariedade horizontal, cujo compromisso caminha por novos trilhos de fazer política na base, ocupando espaços de participação social, seja nos movimentos da sociedade civil, seja através dos conselhos de direitos ou mesmo de suas organizações de base.

Observar seus testemunhos nos remete a olhar a favela pela perspectiva da mulher, que faz desse lugar outro lugar, sob o olhar da moradora que atua como gestora/mediadora/ativista comunitária e que é protagonista de uma nova cena política e social. São histórias e experiências diferenciadas que marcam cada uma delas, mas que convergem no desejo de transformação coletiva de seus lugares de vida e de atuação. Não obedecem às normativas impostas às mulheres desde sempre e estão comprometidas com as lutas comunitárias e populares, inventam e reinventam novas formas de fazer; portanto, transformam o vivido em novos modos de escrever a história - sua e dos outros que as cercam.

E, para finalizar, que fale Sojourner Truth (1851), a maneira de uma oferta de quem tem sabedoria para dar conselhos.

Se a primeira mulher que Deus fez foi forte o bastante para virar o mundo de cabeça para baixo por sua própria conta, todas estas muIheres juntas aqui devem ser capazes de consertá-lo, colocando-o do jeito certo novamente. 


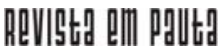

\} MULHER DE FAVELA - NUNES, N. R. A. \}

DOI: $10.12957 /$ rep.2021.56073

\section{Referências}

AKOTIRENE, C. Interseccionalidade. Feminismos Plurais. São Paulo: Editora Pólen, 2019.

ALBUQUERQUE, E. M. de. Avaliação da técnica de amostragem "Respondent-driven Sampling" na estimação de prevalências de Doenças Transmissíveis em populações organizadas em redes complexas. Dissertação (Mestrado em Saúde Pública) - ENSP, Fiocruz, Rio de Janeiro, 2009.

ALVAREZ, S. et al. Encontrando os feminismos latino-americanos e caribenhos. Revista de Estudos Feministas, Florianópolis, v. 11, n. 2, dez. 2003. Disponível em: http://www.scielo.br/scielo.php?script=sci_arttext\&pid =S0104-026X2003000200013\&lng=en\&nrm=iso. Acesso em: 17 fev. 2020.

ALVAREZ, S. E. Para além da sociedade civil: reflexões sobre o campo feminista. Cadernos Pagu, n.43, 2014, pp.13-56. Disponível em: https:// doi.org/10.1590/0104-8333201400430013. Acesso em: 17 fev. 2020.

BIERNACKI, P.; WALDORF, D. Snowball sampling: problems and techniques of chain referral sampling. Sociological Methods \& Research, n. 2, nov. 1981.

CANTO, V. S. do. Outras mulheres: mulheres negras brasileiras ao final da primeira década do século XXI. Rio de Janeiro: Editora PUC-Rio, 2012.

CARNEIRO, S. A. A batalha de Durban. Revista de Estudos Feministas, v. 10, n. 1, 2002. Disponível em: http://dx.doi.org/10.1590/S0104-026 X2002000100014. Acesso em: 18 fev. 2020.

CHAUÍ, M. Notas sobre cultura popular. In: CHAUÍ, M. Cultura e democracia. São Paulo: Cortez, 1990.

COLLINS, P. H. Aprendendo com a outsider within: a significação sociológica do pensamento feminista negro. Sociedade e Estado, vol.31, n.1, 2016, pp.99-127. Disponível em: https://doi.org/10.1590/S0102-69922 016000100006. Acesso em: 12 nov. 2020.

CRENSHAW, K. Documento para o encontro de especialistas em aspectos da discriminação racial relativos ao gênero. Revista de Estudos Feministas, Florianópolis, v. 10, n. 1, jan. 2002. Disponível em: http://www.scielo.br/ scielo.php?script=sci_arttext\&pid=S0104-026X2002000100011\&Ing =en\&nrm=iso. Acesso em: 18 fev. 2020.

DAVIS, A. Mulheres, raça e classe. São Paulo: Boitempo, 2016.

DEL PRIORI, M. Ao sul do corpo: condição feminina, maternidade e mentalidades no Brasil Colônia. São Paulo: Editora Unesp, 2009.

FANON, F. Pele negra, máscaras brancas. Rio de Janeiro: Editora Fator, 1983. 
FERNANDES. F. L. Os jovens da favela. Reflexões sobre controle e contenção sócio-espacial dos párias urbanos no Rio de Janeiro. Convergencia, v. 19. n. 59, maio/ago. 2012. Disponível em: http://www.redalyc.org/articulo. oa? id=10521880007. Acesso em: 22 nov. 2019.

FONSECA, D.; PAGNOCELLI, D. S. M.; MAGALHÃES, M. L. Feminização do poder: considerações iniciais. Revista Praia Vermelha, Rio de Janeiro, n. 18, v. 2, 2008.

GILKES, C. From slavery to social welfare: racism and the control of black women. In: SMERDLOW, A.; LESSINGER, H. (Ed.). Class, race, and sex: the dynamics of control. Boston: G. K. Hall, 1981.

GRAMSCI, A. Os intelectuais e a organização da cultura. Rio de Janeiro: Civilização brasileira, 1979.

GONZALEZ, L. O movimento negro na última década. In: GONZALEZ, L.; HASENBALG, C. Lugar de negro. Rio de Janeiro: Marco Zero, 1982.

HAESBAERT, R. O mito da desterritorialização: do "fim dos territórios" à multi-territorialidade. Rio de Janeiro: Bertrand Brasil, 2004.

HENNING, C. E. Interseccionalidade e pensamento feminista: As contribuições históricas e os debates contemporâneos acerca do entrelaçamento de marcadores sociais da diferença. Dossiê Desigualdades e Interseccionalidades, v. 20, n. 2, 2015.

HEILBORN, M. L.; ARAÚJO, L.; BARRETO, A. (Org.). Gestão de políticas públicas em gênero e raça: módulo III. Brasília: Secretaria de Políticas para as Mulheres, 2010.

hooks, b. Ain't I a woman? Black woman and feminism. Tradução livre para a Plataforma Gueto, jan. 2014. Disponível em: https://plataformagueto. files.wordpress.com/2014/12/nc3a3o-sou-eu-uma-mulher_traduzido.pdf/. Acesso em 12 nov. 2020.

KILOMBA, G. Memórias da plantação: episódios de racismo cotidiano. Rio de Janeiro: Cobodó, 2019.

LEBON, N. Social justice feminism at work: redistribution and recognition in the Marcha Mundial das Mulheres in Brazil. In: LATIN AMERICAN STUDIES ASSOCIATION, Chicago, maio 2014.

LEFEBVRE. H. L' urbain. In: Le retour de la dialectique: douze mots clefs pour le monde moderne. Paris: Messidor/Éditions Sociales, p. 159-173. Tradução de Margarida Maria de Andrade, 1986.

LUGONES, M. Rumo a um feminismo descolonial. Estudos Feministas, Florianópolis, v. 22, n. 3, set./dez., 2014. Disponível em: https://periodicos.ufsc. br/index.php/ref/article/view/36755. Acesso em: 19 fev. 2020. 
MALDONADO-TORRES, N. Transdisciplinaridade e decolonialidade. Revista Sociedade e Estado, v. 31, n. 1, jan./abr. 2016.

NÓBREGA, P. R. DA C. Reflexões acerca dos conceitos de território, territorialidades e redes para o ensino de geografia. Revista de Ensino de Geografia, Uberlândia, v. 4, n. 7, jul./dez. 2013.

PISCITELLI, A. G. A história de um conceito. In: PISCITELLI, A. G.; ALMEIDA, H. B. de; SZWAKO, J. Diferenças, igualdade. São Paulo: Berlendis \& Vertecchia, 2009.

QUIJANO, A. Colonialidade do poder, eurocentrismo e América Latina. Buenos Aires: Clacso, 2005.

RAFFESTIN, C. Por uma geografia do poder. São Paulo: Ática, 1993.

RAGO, M. A aventura de contar-se: feminismos, escrita de si e invenções da subjetividade. Campinas: Editora da Unicamp, 2013.

RATTS, A. Eu sou Atlântica: sobre a trajetória de vida de Beatriz Nascimento. São Paulo: Imprensa Oficial do Estado de São Paulo, 2006.

RIBEIRO, M. Mulheres negras brasileiras: de Bertioga a Beijing. Revista de Estudos Feministas, v. 16, n. 3, dez. 2008. Disponível em: https://perio dicos.ufsc.br/index.php/ref/article/viewFile/16459/15033. Acesso em: 17 nov. 2014.

SAFFIOTI, H. Ontogênese e filogênese do gênero: ordem patriarcal de gênero e a violência masculina contra mulheres. Série Estudos e Ensaios/ Ciências Sociais. FLACSO - Brasil, jun 2009. Disponível em: http://flacso.rede livre.org.br/files/2015/03/Heleieth_Saffioti.pdf. Acesso em: 19 fev. 2020.

SPIVAK, G. C. Pode o subalterno falar? Belo Horizonte: UFMG, 2014.

TELLES, V. S. Favela, favelas: interrogando mitos, dogmas e representações. Revista brasileira de Ciências Sociais, São Paulo, v. 21, n. 62, out. 2006. Disponível em: http://www.scielo.br/scielo.php?script=sci_arttext\&pid= S0102-69092006000300011\&lng=en\&nrm=iso. Acesso em: 20 fev. 2020.

VALLADARES, L. A gênese da favela carioca: a produção anterior às ciências sociais. Revista Brasileira de Ciências Sociais, São Paulo, v. 15, n. 44, 2000.

VALLADARES, L. A invenção da favela: do mito de origem a favela. Rio de Janeiro: Editora FGV, 2005.

VEILLETTE, A. Racialized popular feminism: a decolonial analysis of women's struggle with police violence in Rio de Janeiro's favelas. Latin American Perspective, 2019. [No prelo].

VELASCO, H.; DÍAZ DE RADA, A. La lógica de la investigación etnográfica. Un modelo de trabajo para etnógrafos de la escuela. Madrid: Trotta, 1997.

WERNECK, J.; MENDONÇA, M.; WHITE, E. O livro da saúde das mulheres negras: nossos passos vêm de longe. Rio de Janeiro: Pallas, 2000. 


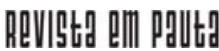

\} MULHER DE FAVELA - NUNES, N. R. A. \}

DOI: $10.12957 /$ rep.2021.56073

WERNECK, J. Os resultados do racismo patriarcal sobre a saúde das mulheres negras são devastadores. Jornal Mulier, n. 85, fev. 2011. Disponível em: www.jornalmulier.com.br. Acesso em: 12 dez. 2019.

WERNECK, J. Racismo institucional e saúde da população negra. Saude e Sciedade, vol.25, n.3, 2016, pp.535-549. Disponível em: https://doi.org/ 10.1590/s0104-129020162610. Acesso em 12 nov. 2020.

DOI: $10.12957 /$ rep.2021.56073

Recebido em 05 de março de 2020.

Aprovado para publicação em 18 de maio de 2020.

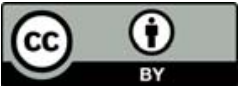

A Revista Em Pauta: Teoria Social e Realidade Contemporânea está licenciada com uma Licença Creative Commons Atribuição 4.0 Internacional. 